\title{
АКТУАЛИЗАЦИЯ ФРЕЙМА В ХУДОЖЕСТВЕННОМ НАРРАТИВЕ (НА МАТЕРИАЛЕ СОВРЕМЕННОЙ РУССКОЙ ПРОЗЫ)
}

Актуальность исследования состоит в том, что при всем многообразии исследований по лингвистическим фреймам, по-прежнему остается открытым вопрос о прагматике языковых выражений, представляющих тот или иной фрейм в тексте (в нашем случае - в русском нарративе), в частности, вопрос о том, каковы те лингвопрагматические средства, посредством которых инициируется фрейм в нарративе. Цель данной статьи состоит в выявлении, описании и классификации языковых выражений, открывающих актуализацию фрейма в художественном нарративе. Исследованию подверглись так называемые онтологические фреймы, представляющие в тексте стереотипные жизненные ситуации и события посредством соответствующих этим фреймам синтаксических структур. При анализе лингвистического материала были выявлены следующие лингвопрагматические средства, инициирующие актуализацию фрейма в художественном нарративе: имя фрейма, макропропозиции фрейма, ядерные пропозиции фрейма, один из слотов актуализируемого фрейма, междуфреймовый переход, дискурсивные пресуппозиции. Отмечено, что инициация фрейма может сопровождаться операциями текстовой импликации, когда содержание фрейма достраивается в результате операций логического вывода. Прагматические пресуппозиции как строевые элементы актуализируемых фреймов также выступают в качестве средств их актуализации, то есть в данном случае прагматические пресуппозиции могут рассматриваться как ядерные пропозиции разных уровней фрейма. За редким исключением, фрейм в художественном нарративе инициируется комплексом лингвопрагматических средств. При этом топонимические фреймы актуализируются посредством имени фрейма и его ядерных пропозиций, но не посредством макропропозиций типа $\mathrm{N}$ есть город. В статье отмечается, что набор средств инициации фрейма весьма разнообразен, при этом анализ материала показал, что чаще употребляются такие средства, как имя фрейма или его слота, макропропозиции, ядерные пропозиции, и наиболее сложным представляется вопрос о выборе автором текста тех или иных языковых средств для инициации фрейма.

Ключевые слова: лингвистическая прагматика, нарратив, фрейм, актуализация фрейма, макропропозиция, ядерная пропозиция, дискурсивные пресуппозиции.

S. V. Gusarenko, M. K. Gusarenko

\section{ACTUALIZATION OF THE FRAME IN LITERARY NARRATIVE (ON THE MATERIAL OF MODERN RUSSIAN PROSE)}

The relevance of the study lies in the fact that with all the diversity of studies on linguistic frames, the question of the pragmatics of language expressions representing a particular frame in the text (in our case, in the Russian narrative) is actual, in particular, what are those linguo-pragmatic means by which the frame is initiated in the narrative. The purpose of this article is to identify, describe and classify linguistic expressions, opening the actualization of the frame in the artistic narrative. The so-called ontological frames, representing stereotypical life situations and events in the text, were subjected to syntax structures corresponding to these frames. When analyzing the linguistic material, the following linguistic and pragmatic means initiating the actualization of the frame in the artistic narrative were identified: the name of the frame, the macroposition of the frame, the nuclear propositions of the frame, one of the slots of the updated frame, the interframe transition, the discursive presupposition. It is noted that frame initiation may be accompanied by textual implication operations, when the frame content is completed as a result of logical inference operations. Pragmatic presuppositions as front elements of actualized frames also act as means of their actualization, that is, in this case, pragmatic presuppositions can be considered as nuclear propositions of different frame levels. With rare exceptions, the frame in literary narrative is initiated by a set of linguistic and pragmatic means. At the same time, toponymic frames are actualized by means of the name of the frame and its nuclear propositions, but not by means of macropositions such as $\mathrm{N}$ is a city. The article notes that the set of means for initiating a frame is very diverse, while the analysis of the material showed that such means as the name of the frame or its slot, macropositions, nuclear propositions are more commonly used, and the most difficult question is whether the author chooses the text to initiate the frame.

Key words: linguistic pragmatics, narrative, frame, frame actualization, macroposition, nuclear proposition, discursive presuppositions. 
Цель данной статьи - выявление, описание и классификация языковых выражений, открывающих актуализацию фрейма в художественном нарративе. Исследованию подверглись так называемые онтологические фреймы, представляющие в тексте стереотипные жизненные ситуации и события посредством соответствующих этим фреймам синтаксических структур. В нашей работе под фреймом мы понимаем когнитивную структуру, сформировавшуюся в результате концептуализации опыта автора/интерпретатора, при этом фрейму конвенционально соответствует определенный набор языковых структур как в когнитивном, так и в текстовом их представлении $[3 ; 7]$. Предполагается, что при прочтении текста представляющие фрейм синтаксические структуры, последовательно подвергаясь оперативной обработке, актуализируют в сознании читателя-интерпретатора соответствующий фрейм [5], что вносит свой вклад в процедуру понимания и интепретации текста [8, с. 65]. Отсюда следует, что автор текста в процессе его создания неизбежно должен учитывать упомянутые выше процедуры и когнитивные процессы, чтобы текст адекватно и без каких-либо специфических операций понимался читателем (за исключением тех случаев, когда такое затруднение понимания текста входит в намерение автора - фигуры умолчания и др.). Эта задача - создание адекватно понимаемого текста - имеет сугубо прагматический характер: ее решение призвано максимально снизить уровень неопределенности относительно «правого контекста», то есть речь идет о снижении информационной энтропии по Уиверу-Шеннону [9], к чему естественным образом стремится всякий читатель, пытающиеся понимать текущий фрагмент текста, чтобы далее понимать последующие части текста.

Представляется, что, приступая к описанию (упоминанию, введению в нарратив) какой-либо ситуации, имеющей свой конвенциональный онтологический фрейм, автор решает специфическую лингво-прагматическую задачу, суть которой состоит в том, чтобы оптимальным образом подобрать языковые выражения, инициирующие актуализацию фрейма в конкретном контекстном фрагменте. То есть фрагмент текста (в том числе весьма протяженный), как правило, содержит последовательность высказываний, конвенционально соответствующих актуализируемому фрейму, мы же подвергли изучение первые высказывания из этой последовательности.

Таким образом, мы исходили из того, что задача автора художественного текста состоит в том, чтобы как можно более точно и компактно представить актуализируемый фрейм. Хотя отметим, что сам автор менее всего думает именно о фрейме, скорее о том, чтобы как можно точнее и по возможности кратко ввести читателя в ситуацию. Отсюда особые прагматические свойства инициирующих синтаксических структур. Задача автора - полная идентификация фрейма читателем.

Анализ фреймовой организации художественного нарратива позволил выделить сюжето- образующие, или сюжетные, фреймы, а также подчиненные им фреймы, включая субфреймы сюжетообразующих фреймов. Сюжетный фрейм репрезентирует в тексте стереотипную ситуацию, явление или событие, которые выступают строевым элементом сюжета, при этом присутствие этого элемента в сюжете строго обусловлено его ролью в адекватном понимании логики повествования и в конечном итоге - понимания событийной канвы всего произведения, включая причинно-следственные связи, его формирующие [3].

Сама по себе последовательность актаулизации и идентификации фрейма в нарративе с позиции читающего уже привлекала внимание исследователей. Так, В. Г. Дуркина предполагает такую последовательность в процедуре актуализации фрейма при прочтении текста: «Восприятие текста представляет собой опознание слотов как слотов конкурирующих фреймов, затем идентификацию фреймов и, наконец, воссоздание «паззла» всего линеарного (нелинейного) содержания текста» $[4$, с. 90]. Соглашаясь в целом с тезисами, выдвинутыми в данном фрагменте, добавим, что, как показал анализ, идентификация фрейма при понимании нарратива может начинаться не только с опознания слота, но также и другими способами, основывающимися на распознавании языковых выражений, которые инициируют актуализацию фрейма в нарративе.

В ходе анализа лингвистического материала были выявлены следующие лингвопрагматические средства, инициирующие актуализацию фрейма в художественном нарративе:

- имя фрейма,

- макропропозиции фрейма,

- ядерные пропозиции фрейма,

- его слот,

- междуфреймовый переход,

- дискурсивные пресуппозиции.

Инициация фрейма может сопровождаться операциями текстовой импликации, когда содержание фрейма достраивается в результате операций логического вывода. К примеру, выражение N окунул младенца в купель и нарек его именем Иван может выступать исходной посылкой для импликации $N$ есть священник, которая выступает содержанием слота СВЯЩЕННИК фррейма КРЕСТИНЫ. Мы также принимаем как естественный тот фракт, что прагматические пресуппозиции как строевые элементы актуализируемых фреймов также выступают в качестве средств их актуализации, то есть в данном случае прагматические пресуппозиции могут рассматриваться как ядерные пропозиции разных уровней фрейма.

Под именем фрейма мы понимаем имя или субстантивное сочетание, которое можно считать конвенциональным именованием того или иного фрейма; к примеру, для культурно адекватного собеседника достаточно употребления в соответствующем контексте слова «крестины», чтобы понять о какой процедуре, о какой последовательности ритуальных действий идет речь; в этом случае мы можем говорить об употреблении имени фрейма. 
Под макропропозицией фрейма мы понимаем пропозицию высказывания [6], описывающего главное событие, действие или состояние, имя которого выступает в качестве субъекта в пропозиции фрейма в нарративе [2]. К примеру, для фрейма КРЕСТИНЫ макропропозицией может выступать пропозиция СОСТОЯЛИСЬ КРЕСТИНЫ.

Под ядерной пропозицией фрейма в нарративе мы будем понимать пропозицию высказывания, в которой в качестве первого и/или второго терма выступают главные участники действия или события [1]. Для фрейма КРЕСТИНЫ ядерной пропозиций может выступать пропозиция СВЯЩЕННИК КРЕСТИЛ МЛАДЕНЦА N.

Когда мы говорим о слоте как о средстве актуализации фрейма, мы имеем в виду языковое выражение, которое само по себе при инициации фрейма выступает как имя одного из его узлов любого уровня. К примеру, в высказывании $N$ встретил своего крестного, выражение своего крестного может рассматриваться как слот соответствующего уровня фрейма КРЕСТИНЫ.

При междуфреймовом переходе (к фрейму того же уровня или к фрейму другого уровня) один из слотов фрейма может выступать субфреймом по отношению к нему, и вэтом случае употребление имени слота будет выступать актуализатором субфрейма. Так, фрейм КРЕСТИНЫ включает сЛот НАРЕЧЕНИЕ ИМЕНЕМ, которЫЙ вЫступает именем субфрейма - речевого акта, неизменно сопровождающего ритуал крещения.

О дискурсивных пресуппозициях как о средстве актуализации фрейма можно говорить в том случае, если в тексте языковое выражение актуализирует соответствующий фрейм, не будучи при этом его специфическим элементом. К примеру выражение Мать завернула младенца в простыню не является специфическим для фрейма КРЕСТИНЫ, однако определяется как его структурный элемент в том случае, если в левом контексте сообщается, что начался обряд крещения.

Отметим также, что, за редким исключением, фрейм в художественном нарративе инициируется комплексом лингвопрагматических средств. При этом отметим, что топонимические фреймы актуализируются посредством имени фрейма и его ядерных пропозиций, но не посредством макропропозиций типа N ecmь город.

Проиллюстрируем полученные теоретические положения фрагментами из первой главы романа И. Ильфа и Е. Петрова «Двенадцать стульев».

1. Актуализация фрейма посредством его имени и ядерных пропозиций

Первая глава Безенчук и «Нимфы» открывается фреймом ГОРОД, который инициируется первым же высказыванием:

(1) В уездном городе N было так много парикмахерских заведений и бюро похоронных процессий, что, казалось, жители города рождаются лишь затем, чтобы побриться, остричься, освежить голову вежеталем и сразу же умереть

Здесь номинация город $N$ представляет собой имя фрейма ГОРОД и актуализирует его. В то же время это имя выступает в составе сирконстанта определяющего целый ряд ядерных пропозиций:

B zороде N есть много парикмахерских заведений

B городе N есть много бюро похоронных процессий

Жители города N рождаются

Жители города N бреются

Жuтели города $N$ стригутся

Жители города N освежают голову вежеталем Жители города N умирают

Таким образом, мы здесь наблюдаем актуализацию фрейма посредством включения имени фррейма и его ядерных пропозиций в единую синтаксическую структуру - сложное предложение. (Приведенные выше пропозиции мы считаем ядерными на том основании, что первым термом в них выступает имя элемента - слота, являющегося непременной составляющей фрейма ГОРОД.)

2. Актуализация фрейма посредством ядерной пропозиции и текстовой импликации - макропропозиции

Актуализация суперфрейма ДЕНЬ СОВЕТСКОГО СЛУЖАЩЕГО, оПределЯющего КомПозиционную структуру всей первой главы, инициируется следующим высказыванием:

(2) Вопросы любви и смерти не волновали Ипполита Матвеевича Воробьянинова, хотя этими вопросами по роду своей службы он ведал с девяти утра до пяти вечера ежедневно с получасовым перерывом для завтрака

В этом высказывании имя суперфрейма ДЕНЬ СОВЕТСКОГО СЛУЖАЩЕГО не прИсУтстВУет, но сам фрейм актуализируется посредством экспликации ядерной пропозиции - Ипполит Mamвеевич Воробьянинов по роду своей службы ведал вопросами любви и смерти с девяти утра до пяти вечера ежедневно с получасовым перерывом для завтрака.

Слот РАБОЧИЙ ДЕНЬ актуализируется посредством сирконстанта с девяти утра до пяти вечера ежедневно с получасовым перерывом для завтрака. Макропропозиция Ипполит Матвеевич Воробьянинов - служащий представляет собой результат импликации, для которой исходными посылками служат сирконстанты по роду своей службы и с девяти утра до пяти вечера ежедневно с получасовым перерывом для завтрака.

3. Актуализация фрейма посредством межфреймового перехода, ядерной пропозиции и дискурсивных пресуппозиций

Актуализируемый фрейм УТРО РАБОЧЕГО ДНЯ яВляется субфреймом фрейма ДЕНЬ СОВЕТСКОГО СЛУЖАЩЕГО и в то же время первым сюжетообразующим фреймом главы. Данный фрейм инициируется следующим высказыванием:

(3) По утрам, выпие из морозного, с жилкой, стакана свою порцию горячего молока, поданного Клавдией Ивановной, он выходил из полутемного домика на просторную, полную диковинного весеннего света улицу имени товарища Губернского. 
Фрейм УТРО РАБОЧЕГО ДНЯ актуализируется посредством ядерных пропозиций, принадлежащих его разным узлам-слотам:

По утрам Воробьянинов выпивает свою порцию горячего молока - слот ЗАВТРАК.

По утрам Воробьянинов выходит из полутемного домика на просторную, полную диковинного весеннего света улицу имени товарища Губернского - слот ВЫХОД НА РАБОТУ.

При этом соотнесение актуализируемого фрейма УТРО РАБОЧЕГО ДНЯ с его суперфреймом ДЕНЬ СОВЕТСКОГО СЛУЖАЩЕГО ОСУЩеСТВЛЯется посредством дискурсивных пресуппозиций Ипполит Матвеевич Воробьянинов - служащий и Ипполит Матвеевич Воробьянинов по роду своей службы ведал вопросами любви и смерти с девяти утра до пяти вечера ежедневно с получасовым перерывом для завтрака, присутствующих в предыдущей части главы.

Особо отметим, что одним из важнейших элементов, определяющих межфреймовый переход, выступает совокупность грамматических характеристик высказываний, инициирующих субфрейм: в данном случае лексическая семантика сирконстанта по утрам определяет значение регулярности, повторяемости действия, описываемого глаголом несовершенного вида выходил, что в свою очередь позволяет соотнести высказывание (3) с фреймом ДЕНЬ СОВЕТСКОГО СЛУЖАЩЕГО как стереотипным представлением повторяющейся ситуации, а не рассматривать это высказывание как описание единичного случая в жизни персонажа.

4. Актуализация фрейма посредством ядерной пропозиции и прагматических пресуппозиций

К сюжетообразующему фреймому УТРО РАБОЧЕГО ДНЯ примыкает следующий сюжетообразующий фрейм РАЗГОВОР С ТЕЩЕЙ, который инициируется посредством представленных ниже высказываний:

(4) <... > Ипполит Матвеевич <.. > учтиво улыбаясь, двинулся навстречу входившей в комнату mеще - Клавдии Ивановне.

(5) - Эполе-эm, - прогремела она, - сегодня я видела дурной сон.

Представляется, что высказывание (4) актуализирует прагматические пресуппозиции, содержащие данные о том, что при встрече люди, как правило, разговаривают. То есть слот РАЗГОВОР может выступать в качестве одной из структурных составляющих фрейма ВСТРЕЧА. В приведенном выше фрагменте встреча происходит в между родственниками - зятем и тещей в комнате дома, где проживают оба, что повышает вероятность разговора между ними при встрече.

Высказывание (5) содержит обращение персонажа к собеседнику Эполе-эт и далее ядерную пропозицию Клавдия Ивановна прогремела [сказала], которые уже непосредственным образом актуализируют фрейм РАЗГОВОР.

Таким же образом актуализируется представленный далее в тексте главы сюжетный фрейм РАЗГОВОР С СОСЕДКОЙ:
(6) В первой комнате Ипполита Матвеевича встретила соседка, агрономша Кузнецова.

(7) Она зашептала и замахала руками.

5. Актуализация фрейма посредством макропропозиции

СюжетНЫЙ фреЙм КОНЕЦ РАБОЧЕГО ДНЯ актуализируется высказыванием:

(8) Служебный день приходил к кониу

Высказывание (10) следует рассматривать как макропропозицию, поскольку оно описывает само сложное событИе КОНЕЦ РАБОЧЕГО ДНЯ, ТО есть располагается на вершине фрейма, в узле верхнего яруса.

Естественно, в актуализации фрейма КОНЕЦு РАБОЧЕГО ДНЯ участвУют и дискурсивные пресуппозиции (в «левом» контексте содержатся сведения, что рабочий день начался, следовательно, в тексте содержатся данные, что когда-то он закончится), но мы описываем минимально достаточные средства актуализации фрейма.

6. Актуализация фрейма посредством включения в текст содержания слота

ПодчиненныЙ фррейм РАЗГОВОР С БЕЗЕНЧУКОМ актуализируется в приведенном ниже фрагменте:

(9) У входа в свое потасканное заведение стоял, прислонивиись к дверному косяку и скрестив руки, гробовых дел мастер Безенчук.

(10) - Как здоровье тещеньки, разрешите узHamb?

Здесь высказывание (10) представляет собой содержание слота РЕЧЕВЫЕ ДЕЙСТВИЯ фрейма РАЗГОВОР.

7. Актуализация фрейма посредством дискурсивных пресуппозиций и импликации

ПодчИненныЙ фрейм РАЗГОВОР С ПОСЕТИТЕЛЯМИ УЧРЕЖДЕНИЯ инИциируется высказЫваниями:

(8) За всеми манипуляциями советского служащего (Ипполита Матвеевича) следили двое молодых людей - мужчина и девица.

(9) Хотя дела своего мужчина в пиджаке еще и не начинал, но уйти ему уже хотелось.

При этом в предыдущем контексте содержатся высказывания, актуализировавшие фрейм учРЕЖДЕНИЕ и выступающие в качестве дискурсивных пресуппозиций, позволяющие идентифицировать именные группы двое молодых людей мужчина и девица как содержание слота ПОСЕТИТЕЛИ УЧРЕЖДЕНИЯ. ЭТа идентификация подтверждается импликацией У мужчины есть дело, выводимой из высказывания (9).

Как видим, набор средств инициации фрейма весьма разнообразен, тем не менее в общих чертах, по-видимому, можно говорить, что выше представлены наиболее распространенные из них. Анализ материала показал, что чаще употребляются такие средства, как имя фрейма или его слота, макропропозиции, ядерные пропозиции. При этом наиболее сложным представляется вопрос о выборе автором текста тех или иных языковых средств для инициации фрейма, и перспективными представляются исследования, в которых будет предпринята попытка объяснения их применения с позиций лингвистической прагматики. 


\section{Литература}

1. Голованова Н. И. Рекурсивная схема актуализации фрейма «вооруженное столкновение» в тексте новостной статьи // Филологические науки. Вопросы теории и практики. 2014. №. 6 (36): в 2-х ч. Ч.І. С. 44-48

2. Голованова Н. И., Гусаренко С. В. Референциально-прагматические аспекты актуализации фрейма «вооруженное столкновение) в тексте новостной статьи // Наука и образование в XXI веке: сборник научных трудов по материалам Международной научно-практической конференции 30 сентября 2013 г.: Часть 7; М-во обр. и науки РФ. Тамбов: Изд-во ТРОО «Бизнес-Наука-Общество», 2013. С. 46-51.

3. Гусаренко С. В., Гусаренко М. К. Фреймовые структуры в когнитивно-семантической организации нарратива // Вопросы когнитивной лингвистики. 2016. №4. С. 33-40.

4. Дуркина Г. С. Фреймовая организация художественного текста (на материале русской классической и современной литературы) // Известия Волгоградского государственного педагогического университета. 2013. №9 (84). С. 90-93.

5. Минский М. Фреймы для представления знаний. М.: Энергия, 1979. $151 \mathrm{c.}$

6. Падучева Е. В. Высказывание и его соотнесенность с действительностью (референциальные аспекты семантики местоимений). 4-е изд. М.: Едиториал, 2004. 288 с.

7. Филлмор Ч. Основные проблемы лексической семантики // Новое в зарубежной лингвистике. 1983. Вып. XII C. $74-122$.

8. Филлмор Ч. Фреймы и семантика понимания // Новое в зарубежной лингвистике: Когнитивные аспекты языка. 1988. Вып. XXIII. C. 52-92.

9. Weaver Warren, Introduction to: Shannon Claude, The Mathematical Theory of Communication, University of Illinois Press, Urbana, 1963.

\section{References}

1. Golovanova N. I. Rekursivnaya skhema aktualizacii frejma «vooruzhennoe stolknovenie» $v$ tekste novostnoj stat'i (Recursive Scheme of Actualization of the Frame "Armed Clash" in the Text of a News Article) // Filologicheskie nauki. Voprosy teorii i praktiki. 2014. No.6(36). Part I. P. 44-48. (In Russian).

2. Golovanova N. I., Gusarenko S. V. Referencial'no-pragmaticheskie aspekty aktualizacii frejma «vooruzhennoe stolknovenie) v tekste novostnoj stat'i (Referential-pragmatic Aspects of Actualization of the "Armed Clash" Frame in the Text of a News Article) // Nauka i obrazovanie v XXI veke: sbornik nauchnyh trudov po materialam Mezhdunarodnoj nauchnoprakticheskoj konferencii 30 sentyabrya 2013 g.: CHast' 7; M-vo obr. i nauki RF. Tambov: Biznes-Nauka-Obshchestvo, 2013. P. 46-51. (In Russian).

3. Gusarenko S. V., Gusarenko M. K. Frejmovye struktury v kognitivno-semanticheskoj organizacii narrativa (Frame Structures in the Cognitive-semantic Organization of the Narrative) // Voprosy kognitivnoj lingvistiki. 2016. No.4. P. 33-40. (In Russian).

4. Durkina G. S. Frejmovaya organizaciya hudozhestvennogo teksta (na materiale russkoj klassicheskoj i sovremennoj literatury) (Frame Organization of a Literary Text (on the Material of Russian Classical and Modern Literature) // Izvestiya Volgogradskogo gosudarstvennogo pedagogicheskogo universiteta. 2013. No.9 (84). P. 90-93. (In Russian).

5. Minskij M. Frejmy dlya predstavleniya znanij. (A Framework for Representing Knowledge). Moscow: EHnergiya, 1979 151 p. (In Russian).

6. Paducheva E. V. Vyskazyvanie i ego sootnesennost's dejstvitel'nost'yu (referencial'nye aspekty semantiki mestoimenij). (The Statement and its Correlation with Reality (Referential Aspects of the Semantics of Pronouns). Moscow: Editorial, 2004. 288 p. (In Russian).

7. Fillmor Ch. Osnovnye problemy leksicheskoj semantiki (Topics in Lexical Semantics) // Novoe v zarubezhnoj lingvistike. 1983. Issue. XII. P. 74-122. (In Russian).

8. Fillmor Ch. Frejmy i semantika ponimaniya (Frames and the Semantics of Understanding) // Novoe $v$ zarubezhnoj lingvistike: Kognitivnye aspekty yazyka. 1988. Issue XXIII. P. 52-92. (In Russian).

9. Weaver Warren, Introduction to: Shannon Claude, The Mathematical Theory of Communication, University of Illinois Press, Urbana, 1963. 